\title{
The Prevalence of People Knowing the Importance of Vitamin D to The Skin in Saudi Arabia \\ Talal Hassan Alsawyan ${ }^{1}$, Adnan Meteb Mohamed Almezani ${ }^{2}$, Mohannad Yousef Aljarallah ${ }^{2}$, Nouf Awwad Algharbi ${ }^{2}$ \\ College of Medicine Al-Imam Muhammad Ibn Saud Islamic University ${ }^{1}$, College of Medicine University of Hail ${ }^{2}$ \\ Corresponding author: Talal Hassan Alsawyan, E-mail: Talal.alsawyan@ hotmail.com, Phone no: +966501444888
}

\begin{abstract}
Background: despite the availability of knowledge and multiple educating social medias, the prevalence of people who know the importance of vitamin D to the skin in Saudi Arabia is decreasing these days.

Objectives: This study was done to know the prevalence of people knowing the importance of vitamin D to the skin in Saudi Arabia.

Methods: a cross-sectional study on knowing the prevalence of people knowing the importance of vitamin D to the skin in Saudi Arabia was done from January to April 2018 on 864 participants within many different social media platforms.

Results: only (36\%) of the participants know the importance of vitamin D to the skin, $(36.7 \%)$ of the participants have checked their vitamin D level at a certain time of point, $(25.1 \%)$ of the participants have been diagnosed with a vitamin D deficiency,( 66\%) of the participants know the sources of vitamin $\mathrm{D},(63.1 \%)$ of the participants know the consequences of vitamin D deficiency, $(42.9 \%)$ of the participants usually get exposed to the sunlight, only (18.3\%) of the participants use vitamin D supplements, $(47.3 \%)$ of the participants know the symptoms of vitamin D deficiency, $(37.8 \%)$ of the participants have a current skin disease and more than half of the participants (55.9\%) think that the society has a role in educating people about the importance of vitamin D.

Conclusion: at the end of this study, there is a decrease number of participants who know the importance of vitamin D to the skin in Saudi Arabia.
\end{abstract}

Keywords: vitamin D, skin, supplements.

\section{INTRODUCTION}

Vitamin $\mathrm{D}$ is very unique because it can be made in the skin from the exposure to the sunlight ${ }^{(1)}$. Vitamin D has two forms. Vitamin D2 which is made from the UV irradiation of the yeast sterol ergosterol and is found naturally in sun-exposed mushrooms. UVB light from the sun insert the skin, and humans synthesize vitamin D3, so it is the most natural form of vitamin $\mathrm{D}$. Human beings do not make vitamin D2, and most oil-rich fish like mackerel and salmon contain vitamin D3. Vitamin D that is ingested in the human body is incorporated into chylomicrons, which are absorbed into the lymphatic system and enters the venous blood. Vitamin D that comes from the skin or diet is biologically not active and requires its first hydroxylation in the liver by the vitamin D-25hydroxylase (25-OHase) to $25(\mathrm{OH}) \mathrm{D}$ (2). However, 25(OH)D requires a further hydroxylation by the $25(\mathrm{OH}) \mathrm{D}-1-\mathrm{OH} a \mathrm{se}$ (CYP27B1) in the kidneys to form the biologically active form of vitamin $\mathrm{D}$ $1,25(\mathrm{OH}) 2 \mathrm{D} \quad{ }^{(2)} \cdot 1,25(\mathrm{OH}) 2 \mathrm{D} \quad$ stimulates intestinal calcium absorption ${ }^{(3)}$. Without the availability of vitamin $D$, only $10-15 \%$ of dietary calcium and about $60 \%$ of phosphorus are absorbed. Vitamin D availability enhances calcium and phosphorus absorption by $30-40 \%$ and $80 \%$, respectively ${ }^{(4)}$.

Vitamin D receptor (VDR) is present in most tissues and cells in the human body ${ }^{(5,6)}$. $1,25(\mathrm{OH}) 2 \mathrm{D}$ has multiple biological functions, such as inhibition of cellular proliferation, inhibiting angiogenesis, stimulating insulin production, inhibiting renin production, stimulating macrophage cathelicidin production and inducing terminal differentiation ${ }^{(7)}$. $1,25(\mathrm{OH}) 2 \mathrm{D}$ may be responsible for regulating up to 200 genes that may facilitate many of the pleiotropic health benefits that have been reported for vitamin $D$ $(8,9)$. Vitamin D has a role in skin differentiation, $1,25(\mathrm{OH}) 2 \mathrm{D}$ has an important and interacting functions in regulating the skin differentiation process. 1,25(OH)2D increases the expression of loricrin, involucrin, transglutaminase and 
filaggrin and increases keratinocytes formation while inhibiting proliferation ${ }^{(10,11)}$. These actions are due to the ability of $1,25(\mathrm{OH}) 2 \mathrm{D}$ to increase intracellular calcium levels achieved by induction of the calcium receptor and the phospholipase $\mathrm{C}$ that are critical for the ability of calcium to stimulate keratinocyte differentiation ${ }^{(12,13)}$. Mice lacking the VDR show defective epidermal differentiation manifesting as reduced levels of involucrin and loricrin and loss of keratohyaline granules ${ }^{(14,15)}$.

\section{MATERIALS AND METHODS}

A cross-sectional study involving 864 participants all over Saudi Arabia was done between January to April 2018. The sample size for this study was selected and distributed randomly. A self-administered questionnaire was developed after a careful review of literature on the subject and it includes 13 questions to people in Saudi Arabia. The questionnaire had two parts. Part one; demographical data that includes age, gender and marital status. Part two; the participants were asked whether they have checked their vitamin D level or not, whether they have vitamin D deficiency or not, do they know the sources of vitamin $\mathrm{D}$, do they know the consequences of vitamin D deficiency, do they know the importance of vitamin $\mathrm{D}$ to the skin, do they usually expose themselves to the sunlight, do they use vitamin D supplements, do they know the symptoms of vitamin D deficiency, whether they think that the society has a role in educating people about the importance of vitamin D or not and whether they a current skin disease or not. Data were collected by through a survey that was distributed through a website-link through participants in Saudi Arabia in different social media sites and platforms. Statistics were descriptively used to describe the answers of the participants in the study using numbers and percentages.

The answers were compared for different questions within the different groups using Pearson chi-square test. Statistical significance was set at $\mathrm{p}<0.05$ and analysis was performed using IBM SPSS statistics, version 23 (IBM, Armonk, NY, USA).

The study was done after approval of ethical board of University of Hail.

\section{RESULTS}

A total of 864 participant women from all over Saudi Arabia were participated in the study and $44.9 \%$ of them are between the ages of 20 to 30 years old, $24.1 \%$ were between 30 to 40 years old, $21 \%$ were between 10 to 20 years old and only $9.3 \%$ were more than 40 years old (Table1). More than half of the participants $57.6 \%$ were single and $42.4 \%$ are married (Table 2). Regarding the participants who have checked their vitamin D level, only $36.7 \%$ of the participants have checked their vitamin D level and $25.1 \%$ have a vitamin D deficiency (Table 3). $66 \%$ of the participants knew some sources of vitamin $\mathrm{D}, 63.1 \%$ of the participants knew the consequences of vitamin D deficiency to the human body, only $36 \%$ of the participants have the experience of the importance of vitamin $\mathrm{D}$ to the skin, only $42.9 \%$ of the participants usually expose themselves to the sunlight and only $18.3 \%$ of the participants use vitamin D supplements and almost half of the participants (Table 4). 47.3\% know the symptoms of vitamin D deficiency (Table 5). $37.8 \%$ of the participants have a current skin disease (Table 6). More than half of the participants $55.9 \%$ thought that the society has a role in educating people about the importance of vitamin D (Table 7).

Table (1): Age distribution of the participants:

\begin{tabular}{|l|l|l|}
\hline Age & Frequency & Percent \\
\hline $1-10$ & 7 & 0.7 \\
\hline $10-20$ & 181 & 21 \\
\hline $20-30$ & 388 & 44.9 \\
\hline $30-40$ & 208 & 24.1 \\
\hline$>40$ & 80 & 9.3 \\
\hline Total & 864 & 100 \\
\hline
\end{tabular}


The Prevalence of People Knowing the Importance of Vitamin D to The Skin in Saudi Arabia

Table (2): Marital status and gender of the participants:

\begin{tabular}{|l|l|l|}
\hline $\begin{array}{l}\text { Marital } \\
\text { status }\end{array}$ & Frequency & Percent \\
\hline Single & 498 & 57.6 \\
\hline Married & 366 & 42.4 \\
\hline Total & 864 & 100 \\
\hline Gender & & \\
\hline Male & 585 & 67.7 \\
\hline Female & 279 & 32.3 \\
\hline Total & 864 & 100 \\
\hline
\end{tabular}

Table (3): Participants who checked their vitamin D and have vitamin D deficiency:

\begin{tabular}{|l|l|l|}
\hline Checked vitamin D & Frequency & Percent \\
\hline Yes & 317 & 36.7 \\
\hline No & 547 & 63.3 \\
\hline Total & 864 & 100 \\
\hline Have vitamin D deficiency & \multicolumn{2}{|l|}{} \\
\hline Yes & 217 & 25.1 \\
\hline No & 108 & 12.5 \\
\hline I don't know & 539 & 62.4 \\
\hline Total & 864 & 100 \\
\hline
\end{tabular}

Table (4): Multiple questions about the participants and vitamin D:

\begin{tabular}{|l|l|l|}
\hline Know the sources of vitamin D & Frequency & Percent \\
\hline Yes & 570 & 66 \\
\hline No & 294 & 34 \\
\hline Total & 864 & 100 \\
\hline Know the consequences of vitamin D deficiency & 63.1 \\
\hline Yes & 545 & 36.9 \\
\hline No & 319 & 100 \\
\hline Total & 864 & \multicolumn{2}{l|}{} \\
\hline Know the importance of vitamin D to the skin & 36 \\
\hline Yes & 311 & 64 \\
\hline No & 553 & 100 \\
\hline Total & 864 & \multicolumn{2}{l|}{} \\
\hline Usually get exposed to the sunlight & \multicolumn{2}{|l|}{} \\
\hline Yes & 371 & 42.9 \\
\hline No & 493 & 57.1 \\
\hline Total & 864 & 100 \\
\hline Use vitamin D supplements & 158 & 18.3 \\
\hline Yes & 706 & 81.7 \\
\hline No & 864 & 100 \\
\hline Total & & \multicolumn{2}{l|}{} \\
\hline
\end{tabular}

Table (5): Participants who know the symptoms of vitamin D deficiency:

\begin{tabular}{|l|l|l|}
\hline $\begin{array}{l}\text { Know the symptoms of vitamin D } \\
\text { deficiency }\end{array}$ & Frequency & Percent \\
\hline Yes & 409 & 47.3 \\
\hline No & 455 & 52.7 \\
\hline Total & 864 & 100 \\
\hline
\end{tabular}

Table (6): Participants who have a current skin disease:

\begin{tabular}{|l|l|l|}
\hline Have a current skin disease & & \\
\hline Yes & 327 & 37.8 \\
\hline No & 537 & 62.2 \\
\hline Total & 864 & 100 \\
\hline
\end{tabular}


Table (7): Participants who think that the society has a role in educating people about the importance of vitamin $\mathrm{D}$ :

\begin{tabular}{|l|l|l|}
\hline $\begin{array}{l}\text { Think that the society has a role in } \\
\text { educating people about the } \\
\text { importance of vitamin D }\end{array}$ & Frequency & Percent \\
\hline Yes & 483 & 55.9 \\
\hline No & 381 & 44.1 \\
\hline Total & 864 & 100 \\
\hline
\end{tabular}

\section{DISCUSSION}

In the present study, we found that there was an increased number of people who do not know the importance of vitamin $\mathrm{D}$ to the skin. Vitamin D has a role in preventing multiple disorders like psoriasis, skin cancer, ichthyosis, autoimmune skin disorders such as vitiligo, blistering disorders, scleroderma and systemic lupus erythematosus, as well as atopic dermatitis, acne, hair loss, infections and photodermatoses ${ }^{(16)}$. Even though, it remains speculative whether vitamin D deficiency primarily contributes to disease pathogenesis or merely represents a consequential event to the inflammation processes that occurs. A recent systematic review including 290 prospective cohort studies and 172 randomized trials of major health outcomes and of physiological parameters related to disease risk or inflammatory status showed that there is one solid fact is emphasized; vitamin D deficiency appears to be a marker of illness to health regardless of being an actual cause or an association ${ }^{(16)}$. Vitamin D has a role in skin differentiation and proliferation since both calcium and 1,25(OH)2D perform important and interacting functions in regulating the skin differentiation process ${ }^{(17)} \cdot 1,25(\mathrm{OH}) 2 \mathrm{D}$ causes an increase in the expression of transglutaminase, involucrin, loricrin, and filaggrin and increases keratinocyte envelope formation while inhibiting proliferation process (18). Vitamin D has arole in wound healing process since 1,25-Dihydroxyvitamin D3 regulates the expression of cathelicidin an antimicrobial protein that appears to mediate innate immunity in skin by promoting wound healing and tissue repair ${ }^{(19)}$. This shows that (36.7) \% of the participants have not checked their vitamin $\mathrm{D}$ level and (25.1\%) of the participants have a vitamin D deficiency. $37.8 \%$ of the participants have a current skin disease and almost half of them $(44.1 \%)$ don not think that the society has a role in educating people about the importance of vitamin $\mathrm{D}$ deficiency which reflects the present status than a huge number of the participants have not checked their vitamin D level.

\section{CONCLUSION}

We can conclude that there is an increased number of people who do not know the importance of vitamin D to the skin in Saudi Arabia. People should pay more attention to their vitamin D level and how to deal with a deficiency once occurred since vitamin D affects the skin and the whole body in general. Society and doctors should inform and teach people about the importance of vitamin $\mathrm{D}$ to the skin and how to know the early symptoms of vitamin D deficiency.

\section{REFRENCES}

1. Lips $\mathbf{P}$, Hosking D, Lippuner $\mathrm{K}$ et al. (2006): The prevalence of vitamin $D$ inadequacy amongst women with osteoporosis: An international epidemiological investigation. J Intern Med,. 260:245-54

2. MedlinePlus (2010): 25-hydroxy vitamin $D$ test. Available at: https://medlineplus.gov/ency/article/0 03569.htm

3. Moyad MA (2009): Vitamin D: A rapid review: Side effects and toxicity. Available at: http://accurateclinic.com/wpcontent/uploads/2016/02/Vitamin-DA-Rapid-Review-2009.pdf

4. Lappe JM, Travers G, Davies KM et al. (2007): Vitamin D and calcium supplementation reduces cancer risk: Results of a randomized trial. Am J Clin Nutr., 85:1586-91.

5. Harvard School of Public Health Nutrition Source (2010): Vitamin D and health. Available at: https://www.hsph.harvard.edu/nutritio nsource/what-shouldyou-eat/vitamind/index.html

6. Chlebowski RT, Johnson KC, Kooperberg $\mathrm{C}$ et al. (2008): Calcium 
plus vitamin $\mathrm{D}$ supplementation and the risk of breast cancer. J Natl Cancer Inst.,100:1581-91.

7. Stolzenberg S, Hayes RB, Horst RL et al. (2009): Serum vitamin D and risk of pancreatic cancer in the Prostate, Lung, Colorectal, and Ovarian Screening Trial. Cancer Res., 69:143947.

8. Standing Committee on the Scientific Evaluation of Dietary Reference Intakes Food and Nutrition Board, Institute of Medicine (2010): Dietary Reference Intakes for Calcium, Phosphorus, Magnesium, Vitamin D, and Fluoride. Chapter 7. Available at: https://www.nap.edu/read/5776/chapte $\mathrm{r} / 1$

9. NIH Office of Dietary Supplements. Dietary supplement fact sheet: Vitamin D (2010): Available at: https://ods.od.nih.gov/factsheets/Vita minD-HealthProfessional/

10. Bikle D, Pillai S (1993): Vitamin D, calcium, and epidermal differentiation. Endocr Rev, 14:3-19.

11. Hawker N, Pennypacker S, Chang S et al. (2007): Regulation of human epidermal keratinocyte differentiation by the vitamin $\mathrm{D}$ receptor and its coactivators. J Invest Dermatol., 127:874.

12. Tu C, Chang W, Bikle D (2001): The extracellular calcium-sensing receptor is required for calcium-induced differentiation in human keratinocytes. $\quad J \quad$ Biol Chem., 276:41079-41085.

13. Xie Z, Bikle D (2001): Inhibition of 1,25-dihydroxyvitamin-D-induced keratinocyte differentiation by blocking the expression of phospholipase C-gamma1. J Invest Dermatol., 117:1250-1254.

14. Bikle D, Elalieh H, Chang $S$ et al. (2006): Development and progression of alopecia in the vitamin $D$ receptor null mouse. J Cell Physiol., 207:340353.

15. Xie Z, Komuves L, Yu Q et al .(2002): Lack of the vitamin D receptor is associated with reduced epidermal differentiation and hair follicle growth. J Invest Dermatol., 118:11-16.

16. Autier $P$, Boniol M, Pizot $C$ et al. (2014): Vitamin D status and ill health: a systematic review. Lancet Diabetes Endocrinol., 2:76-89

17. Bikle D, Pillai S (1993): Vitamin D, calcium, and epidermal differentiation. Endocr Rev., 14:3-19.

18. Hawker N, Pennypacker S, Chang S et al. (2007): Regulation of human epidermal keratinocyte differentiation by the vitamin $\mathrm{D}$ receptor and its coactivators DRIP205, SRC2, and SRC3. J Invest Dermatol., 127:874.

19. Schauber J, Dorschner R, Coda A et al. (2007): Injury enhances TLR2 function and antimicrobial peptide expression through a vitamin Ddependent mechanism. J Clin Invest., 117:803-811. 